Article

\title{
Investigation of Using Sol-Gel Technology for Corrosion Protection Coating Systems Incorporating Colours and Inhibitors
}

\author{
Wenjin Yan, Wee Kit Ong, Linda Yongling Wu *(D) and Sudesh L. Wijesinghe * \\ Agency for Science, Technology and Research (A*STAR), Singapore Institute of Manufacturing Technology \\ (SIMTech), Singapore 138634, Singapore; yan_wenjin@SIMTech.a-star.edu.sg (W.Y.); \\ ong_wee_kit@SIMTech.a-star.edu.sg (W.K.O.) \\ * Correspondence: ylwu@simtech.a-star.edu.sg (L.Y.W.); sudeshw@SIMTech.a-star.edu.sg (S.L.W.); \\ Tel.: +65-64197425 (L.Y.W.); +65-64197424 (S.L.W.)
}

Received: 30 November 2018; Accepted: 14 January 2019; Published: 16 January 2019

\begin{abstract}
Corrosion protection coatings need frequent developments to cater to different challenges arising from users. In addition to a long lasting corrosion protection, aesthetic requirements and multi-functional properties by the same coating system are prominent demands to be considered. Productivity is another vital factor to be considered, as there is a thriving demand from users to have more productive coating systems, such as a smaller number of layers in a system. Thus, attention to using different coating technologies is an essential step to fulfil these demands. This work investigates the use of sol-gel technology as a topcoat on a zinc rich primer to form a two-coat system. A colored sol-gel topcoat on a zinc primer was developed as a two-coat system to replace the current three or multi-coat systems to improve productivity while maintaining the sacrificial protective capability. The overall corrosion protection performance together with the color retaining capability was evaluated in this development. As another step forward, the development of sol-gel technology as a topcoat with additional inhibitive corrosion protection was investigated. Two corrosion inhibitors, namely molybdate and cerium(III), were loaded onto suitable inorganic oxide carriers and then incorporated into sol-gel coatings to provide an inhibitive protection other than the barrier protection. The corrosion performance of the coatings was evaluated using electrochemical impedance spectroscopy (EIS). Sol-gel coating with a cerium(III) system attained the highest impedance and proved to be the best candidate. The mechanical and physical properties of the coating systems are tested using international standard methods.
\end{abstract}

Keywords: sol-gel coating; corrosion protective coating system; two-coat system; corrosion inhibitor; electrochemical impedance spectroscopy

\section{Introduction}

Coatings play a major role in saving cost and preventing failures due to corrosion. Progress and numerous advances have been made in corrosion protection coating technologies. There is an increasing demand from various sectors in the industry for cost-effective coatings with enhanced protection and multi-functional capabilities. However, current developments are still not adequate in some aspects of the industry supply chain. This poses the challenge of having coatings with multi-functional properties without compromising the corrosion protection capabilities. The interest in multi-functional properties differs from one application to another. These include aesthetic requirements, wear and abrasion resistance, and also fire and thermal resistance. Furthermore, industries are always looking for innovative ways to gain more revenue by increasing their productivity. One such example is through a cost-effective process that consists of a coating system with less layers. 
The main challenge in this case is to provide a coating with similar or better corrosion protection, together with other functional properties and uncompromised adhesion. Selecting a suitable coating system for further developments to achieve this goal is the first step towards success.

Sol-gel coatings have been used for various applications including corrosion protection in the past few decades [1-5]. As discussed widely, sol-gel coatings have many advantages-(a) a relatively low process temperature [6], (b) a good chemical resistance and thermal stability [3,7], (c) a versatile process to add multi-functions, such as superhydrophobicity [8], scratch-resistance [4], self-cleaning [5] etc., and also (d) environmental friendliness [1,6]. Investigations on sol-gel coatings for their corrosion protection capabilities are also widely reported $[1,2,9,10]$. Currently, most of the sol-gel coatings were used to protect metal/alloy substrates, like aluminum [1,2], magnesium $[4,11]$, stainless steel $[12,13]$ and carbon steel $[10,14]$. There is much investigation on the influences of formula $[12,15,16]$ and process conditions, such as the surface condition $[17,18]$ and the curing temperature [19] on the corrosion protective performance of sol-gel coatings. Ferreira [1,9,20-24], Montemor [1,24-26], Zheludkevich [1,9,20,27-29], Duran [30-33], have done extensive work on the usage of sol-gel as a corrosion protective coating. Some of their works include the incorporation of corrosion inhibitors into sol-gel coatings to provide additional inhibitive protection against corrosion $[9,22,23,25-29,34]$.

Zinc based coatings are used in various applications due to their sacrificial corrosion protection properties. Although hot-dip galvanizing is widely use in this aspect, there has been an increasing demand in recent years for zinc rich coatings to replace hot-dip galvanizing for some applications. One major issue with zinc rich coatings is their appearance, because the color of zinc is not aesthetically attractive in some applications.

To provide a colored presence to zinc rich primers, a common practice is to apply multi layers, which could be as many as four additional layers of coatings. The intermediate layers are used to enhance the adhesion and compatibility of the coating system. However, this is a major drawback to industries in terms of productivity and cost, as more raw-materials and manpower are required. This may also restrict the sacrificial protection properties of the zinc primer.

The present work aimed to investigate the use of sol-gel technology as a top coat for a zinc rich primer in a two-coat system. The compatibility between the two layers was considered in this development to investigate the overall performance using accelerated corrosion tests. In addition, initial developments in sol-gel technology as a top coat with enhanced corrosion properties were also studied. A commercial zinc rich coating system was used to benchmark the corrosion protection performance. Various corrosion inhibitors such as molybdate and cerium(III) were added to the sol-gel coating to study their effects on corrosion protection properties. Electrochemical impedance spectroscopy (EIS) or accelerated salt spray test were used to evaluate the corrosion performance of the various coatings.

\section{Materials and Methods}

\subsection{Materials}

Tetraethyl orthosilicate (TEOS, Sigma-Aldrich, Singapore) and (3-glycidyloxypropyl)trimethoxysilane (GLYMO, Sigma-Aldrich) were used as sol-gel precursors. Itaconic acid ( $\geq 99 \%$, Sigma-Aldrich) was used as the hydrolysis catalyst, while LUDOX ${ }^{\circledR}$ AS- 40 colloidal silica (Sigma-Aldrich) was added to enhance the coating mechanical properties. The corrosion inhibitors used in this report include sodium molybdate (Sigma-Aldrich) and cerium(III) nitrate hexahydrate (Sigma-Aldrich). The carriers used for inhibitor entrapment were bentonite (Sigma-Aldrich) and hydrotalcite (Sigma-Aldrich). Heliogen Green L8605 (BASF, Singapore) was used to provide green color, while Degussa P25 $\mathrm{TiO}_{2}$ (Evonik, Singapore) was used as the pore filler and color tuner. All chemicals were used as received without further purification. A36 carbon steel was used as the coating substrate.

MS-52M Multi Position Magnetic Stirrer (Lab Companion, Jeio Tech Co., Ltd., Seoul, Korea) was used to prepare inhibitor loaded materials and sol-gel. LUNA-L-LD-1.0 Low Volume Medium Pressure (LVMP) Spray Gun (DeVILBISS, Scottsdale, AZ, USA) was used to apply spray coating. 


\subsection{Inhibitor Loading Process}

The ion-exchange process was employed to prepare two different corrosion inhibitor loaded materials. Bentonite was used to entrap cerium(III) and the product was named Ce-BTN in this work. Similarly, hydrotalcite was used to entrap molybdate and the product was named Mo-HT in this work. The solid carrier was added into the aqueous inhibitor solution and stirred for $24 \mathrm{~h}$. The mixture was centrifuged at $5000 \mathrm{rpm}$ for $10 \mathrm{~min}$, then the residue was washed with ethanol three times. The slurry was dried at $80^{\circ} \mathrm{C}$ for $24 \mathrm{~h}$, before being ground into fine powders.

\subsection{Coating Preparation}

The commercial zinc rich coating systems were prepared by a spray coating technique, following the instruction by the technical data sheet (TDS) and the application guide. A36 carbon steel substrates were cut into $100 \mathrm{~mm} \times 150 \mathrm{~mm} \times 3 \mathrm{~mm}$ and sandblasted to comply with SA2.5, according to the International Standard ISO 8501 [35].

The formula of sol-gel coating was reported in our previous work [36]. TEOS and GLYMO were mixed with in molar ratio of 3:2 and hydrolyzed in $0.5 \mathrm{M}$ itaconic acid solution, with the presence of $5 \mathrm{wt} . \%$ LUDOX ${ }^{\circledR}$ AS-40. The mixture was stirred under $500 \mathrm{rpm}$ for 72 to $120 \mathrm{~h}$ to ensure a complete hydrolysis before aging. Before the spray application, Heliogen Green L8605 and Degussa P25 $\mathrm{TiO}_{2}$ blend was ball-milled overnight and added into the coating solution to tune the color. The inhibitor loaded material was also added at this stage, if needed. The sol-gel coating was applied by spray coating technique and cured at $150{ }^{\circ} \mathrm{C}$ for $30 \mathrm{~min}$. For the two-coat system, zinc rich primer was simply cleaned by compressed air, before the application of sol-gel coating. To prepare the samples for electrochemical analysis, the A36 carbon steel substrate was pre-finished by sandblasting with \#120 aluminum oxide for the direct application of sol-gel coating.

\subsection{Characterizations}

The pencil hardness of sol-gel coating was evaluated following the international standard ASTM D3363 [37]. The adhesion of the coating systems was evaluated by cross hatch testing (international standard ASTM D3359 [38]). The thickness of the coating was verified by Elcometer 456 coating thickness gauge (Elcometer, Manchester, UK).

The corrosion protection performance of the coated samples was evaluated after the exposure to continuous salt fog conditions according to ASTM B117 [38], using an accelerated exposure corrosion chamber (SF-500, Atlas, Mount Prospect, IL, USA). Both scribed and non-scribe samples were used to assess the sacrificial and overall corrosion/degradation protection properties.

Image analyzing software (Olympus Stream Essentials, Version 2.3.2) was used to quantify the percentage of rust on the samples. High resolution photographs were taken on gently washed and dried samples. Software was used to distinguish the appearance of different products based on contrast variations for each pixel. The percentages of each different product were quantified at various time intervals using the software.

Electrochemical impedance spectroscopy (EIS) was utilized to evaluate the coating performance using a Reference 600+ potentiostat (Gamry Instruments, Warminster, PA, USA). A standard three electrode system was used with a coated carbon steel of $100 \mathrm{~mm} \times 150 \mathrm{~mm} \times 3 \mathrm{~mm}$ (exposed area $=10 \mathrm{~cm}^{2}$ ) as the working electorate, and a graphite rod as the counter electrode and a saturated calomel electrode (SCE) as the reference electrode. The experiments were performed in $0.1 \mathrm{wt} . \%$ chloride solution and the frequency ranged from $10^{5}$ to $0.1 \mathrm{~Hz}$ over an alternating voltage of $10 \mathrm{mV}$ amplitude. The EIS results were analyzed using Gamry Echem Analyst (Version 6.33).

\section{Results}

\subsection{Evaluation of Commercial Zinc Rich Coating System}

In this work, a commercial zinc rich primer and a three-coat system (with the same zinc primer) were used for benchmarking. Figure 1 presents the photographic evidence of these coatings systems 
after exposure for 30 days. The samples were removed from the corrosion test chamber periodically for evaluation along the exposure period of 30 days. The non-damaged commercial three-coat system showed excellent corrosion resistance, while keeping its aesthetic appearance as seen in Figure 1c. However, the sacrificial corrosion ability of this three-coat system was greatly compromised in the presence of a scribe. Red rust started appearing along the scribe after 10 days as seen in Figure $1 \mathrm{~d}$ and further deteriorated along prolong exposure. Clearly, the additional topcoat layers significantly compromised the sacrificial corrosion protection capability, which is critical when the coating system is damaged. One of the main causes of such a failure can be an insufficient interlayer adhesion, although the details of the failure can be rather complex.
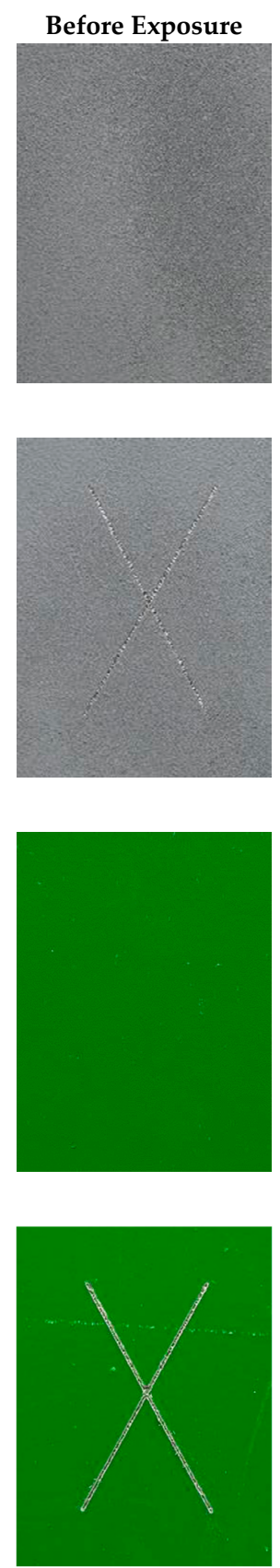
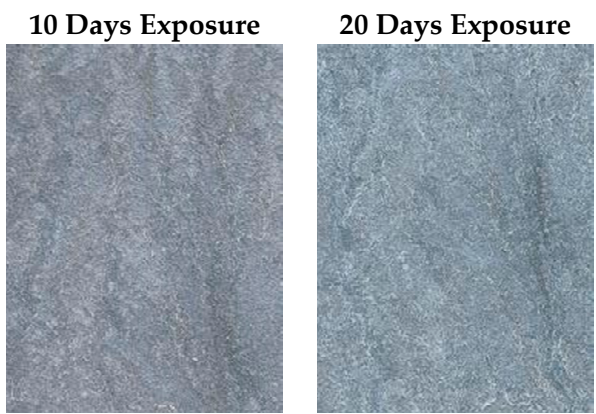

(a)
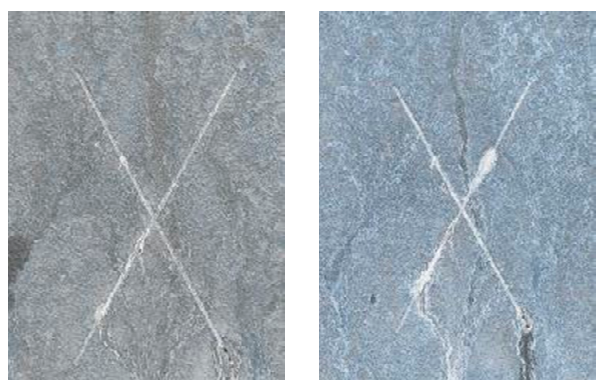

(b)
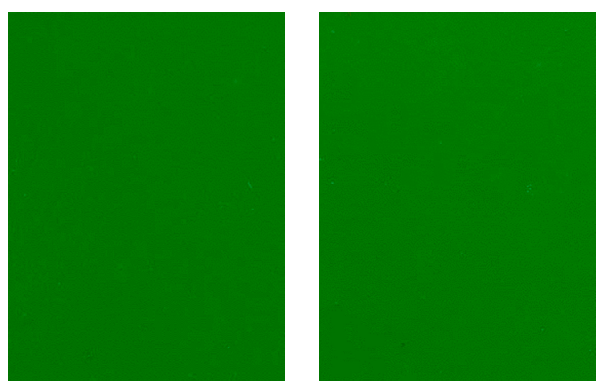

(c)
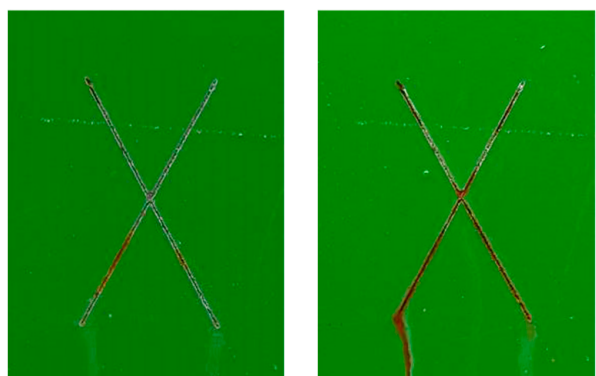

(d)
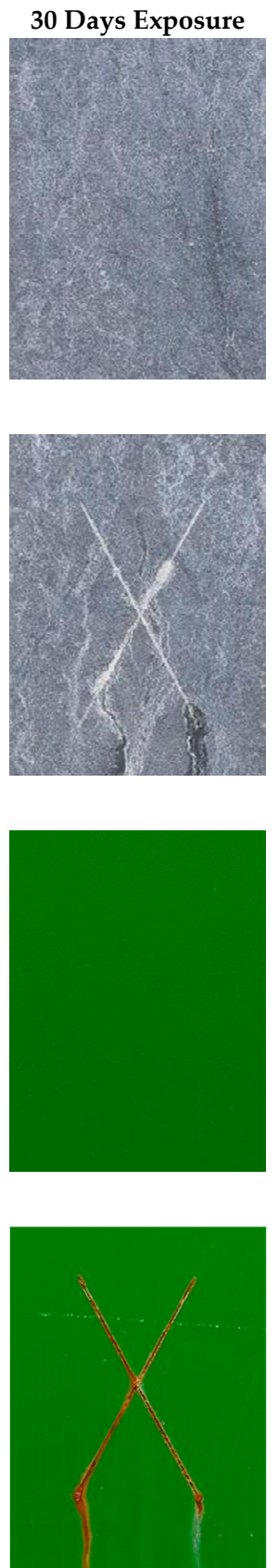

Figure 1. Appearance of coating systems after accelerated exposure corrosion test of $(\mathbf{a}, \mathbf{b})$ Commercial $80 \mu \mathrm{m}$ zinc rich primer and (c,d) Commercial three-coat system $(80 \mu \mathrm{m}$ zinc rich primer, $100 \mu \mathrm{m}$ intermediate layer, $50 \mu \mathrm{m}$ top coat). (a,c) non-scribe; (b,d) scribe. 


\subsection{Two-Coat System with Sol-Gel Topcoat}

The same commercial zinc rich primer with $80 \mu \mathrm{m}$ thickness (used in Section 3.1) was used as the base coat to develop the two-coat system with a sol-gel topcoat, the thickness of which was varied between 20 and $30 \mu \mathrm{m}$. Considering the silicate binder in this primer, a colored sol-gel topcoat was developed to form a two-coat system. Table 1 presents the mechanical and physical coating properties of this two-coat system. According to ASTM D3363 [37] (pencil hardness test), the hardness of the sol-gel topcoat is classified under " $2 \mathrm{H}^{\prime}$. Furthermore, a cross hatch asdhesion test was performed on the coating and achieved a rating of " $4 \mathrm{~B}$ " according to ASTM D3359 [38].

Table 1. Basic coating properties of two-coat system with sol-gel topcoat.

\begin{tabular}{cc}
\hline Description & Property \\
\hline pencil hardness test & $2 \mathrm{H}$ \\
cross hatch adhesion test & $4 \mathrm{~B}$ \\
topcoat thickness & $20-30 \mu \mathrm{m}$ \\
\hline
\end{tabular}

The hardness value of the sol-gel coating according to the pencil hardness test is $2 \mathrm{H}$, which shows enhanced mechanical property of the coating system, as the hardness of the zinc rich primer used is HB. According to the cross hatch test result suggested the strong adhesion of this two-coat system. The involvement of GLYMO in the sol-gel topcoat improves the flexibility of the coating for better interfacial adhesion.

For the two-coat system developed, the $80 \mu \mathrm{m}$ zinc rich primer is the same commercial one as in Figure 1. The sol-gel topcoat (TC1) was $20 \mu \mathrm{m}$ in thickness. The two-coat system samples were also placed in the accelerated exposure corrosion chamber. Similar to the procedures for the commercial samples, a mechanical damage was made to the coating and subsequent exposure results are presented in Figure 2. In contrast to the commercial three-coat system, the sacrificial corrosion protection capability was well retained in this two-coat system. As seen in Figure 2, no red rust of the steel substrate was observed in the scribe upon 30 days of exposure, suggesting that the additional sol-gel topcoat did not adversely affect the sacrificial protection of the zinc rich primer. However, close to $6 \%$ of the coating area was covered with white rust, due to zinc corrosion after 30 days of exposure. This may imply retaining of sacrificial protection property of zinc layer though aesthetic appearance was affected due to formation of white rust.

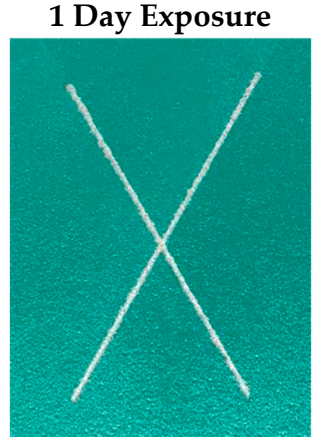

(a)

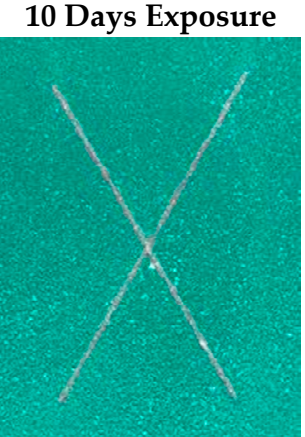

(b)

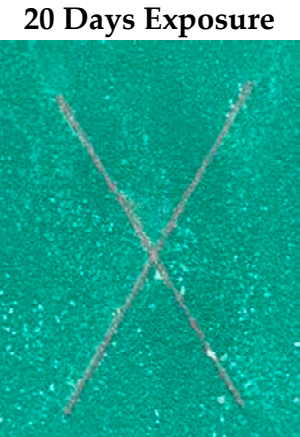

(c)

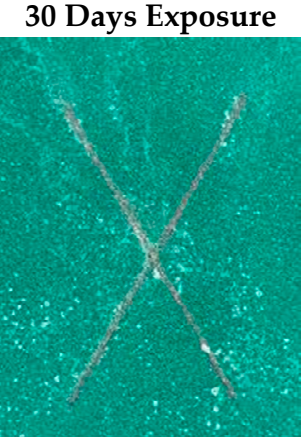

(d)

Figure 2. Appearance of coating system after accelerated exposure corrosion test of two-coat system with scribe. The values indicated below the images are the percentages of white rust area over the total area: (a) N.A.; (b) $2.43 \%$; (c) $4.28 \%$; (d) $6.30 \%$.

We hypothesized that the presence of the white rust on the surface was due to the porous nature of the sol-gel coating caused by relatively lower curing temperature used in this work. The pores provided a pathway for moisture to migrate into the coating and reach the zinc primer layer to form 
the white rust. Thus, the porosity should be minimized to retain the color in long term use and to maintain the sacrificial protection properties at the same time.

The preparation parameters of the sol-gel coating were varied as described in Table 2. As shown, the effects of the curing duration, curing temperature and coating thickness were investigated. A longer curing duration and / or higher curing temperature would reduce the porosity of the sol-gel coating [39] and thus reduce the amount of white rust on the surface. With a thicker topcoat, the pathway for the white rust to reach the surface would be longer. The accelerated exposure results of the improved two-coat system samples are provided in Figure 3. These results confirmed the above hypothesis, as significantly less white rust was observed on these improved coating systems. To show the corrosion protection performance and color retainment, the test results after 20 days (500 h), 42 days $(1000 \mathrm{~h})$ and 84 days $(2000 \mathrm{~h})$ are provided in Figure 3. By comparing the TC1 system with TC2 system, we confirmed that the coating system with a longer curing duration reduced the white rust presence on the surface. The improved performances of TC3 system against TC1 system suggests the positive effect of the higher curing temperature which is more effective than longer curing duration. Please confirm meaning is retained Additional topcoat thickness (TC4 system) prolongs the presence of white rust, due to the longer pathway for the growth of white rust from the coating interface to the surface of topcoat.

Table 2. Curing temperature and duration of sol-gel topcoat with their respective thickness values.

\begin{tabular}{ccc}
\hline Sample ID & Curing Conditions & Thickness \\
\hline TC1 & $150^{\circ} \mathrm{C}, 30 \mathrm{~min}$ & $20 \mu \mathrm{m}$ \\
TC2 & $150^{\circ} \mathrm{C}, 120 \mathrm{~min}$ & $20 \mu \mathrm{m}$ \\
TC3 & $160^{\circ} \mathrm{C}, 30 \mathrm{~min}$ & $20 \mu \mathrm{m}$ \\
TC4 & $150^{\circ} \mathrm{C}, 30 \mathrm{~min}$ & $30 \mu \mathrm{m}$ \\
\hline
\end{tabular}

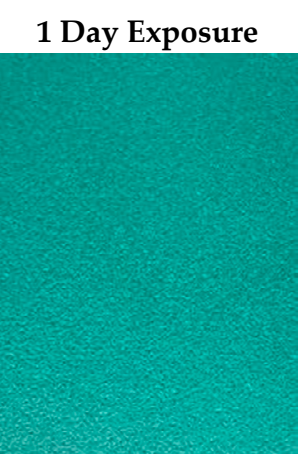

$0.00 \%$

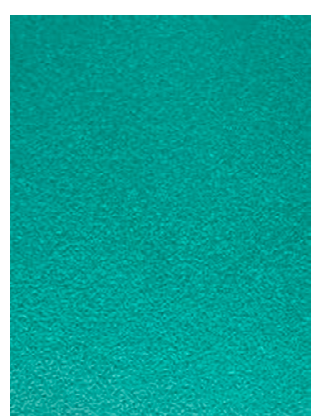

$0.00 \%$
20 Days Exposure

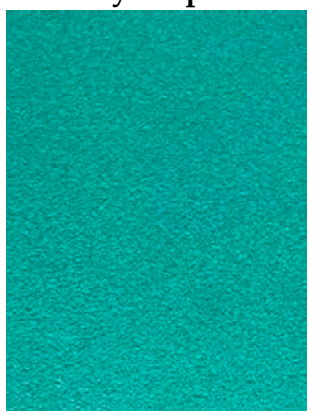

$0.00 \%$

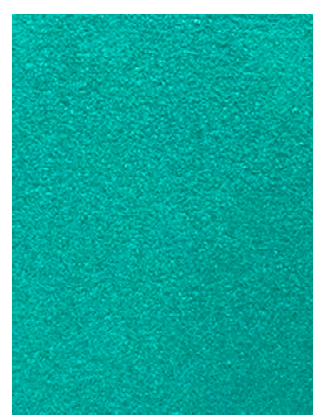

$0.00 \%$
42 Days Exposure

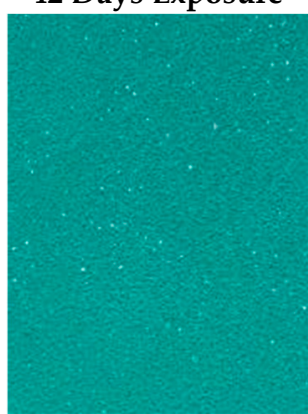

$0.64 \%$

(a)

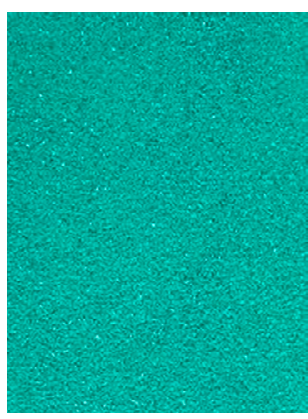

$0.46 \%$

(b)
84 Days Exposure

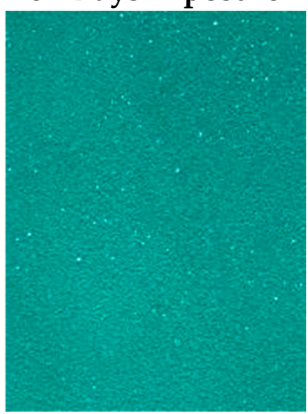

$1.90 \%$

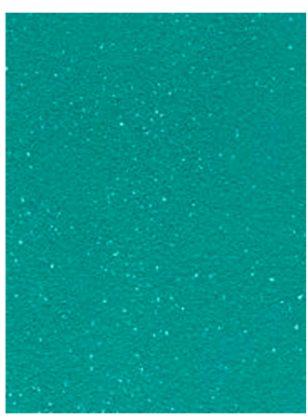

$0.93 \%$

Figure 3. Cont. 


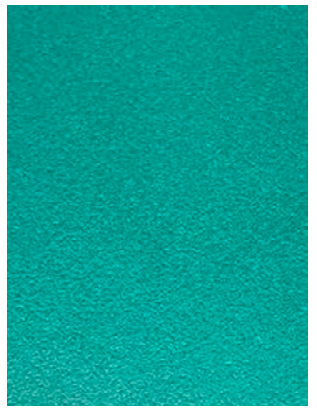

$0.00 \%$

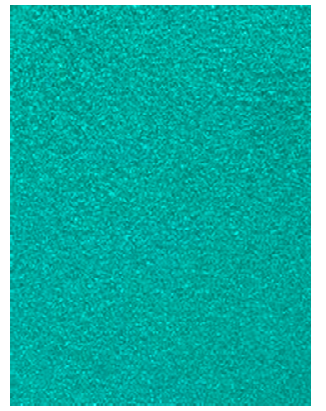

$0.00 \%$

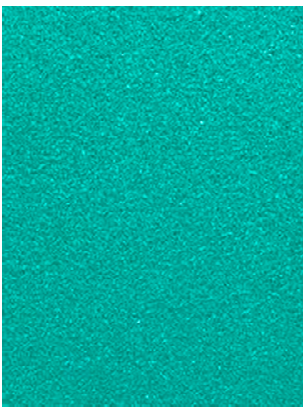

$0.78 \%$

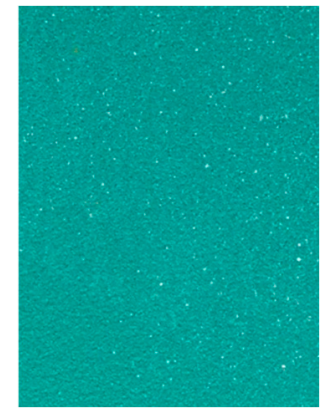

$1.80 \%$

(c)

Figure 3. Appearance of coating systems (80 $\mu \mathrm{m}$ zinc rich primer with (a) $20 \mu \mathrm{m}$ TC2 topcoat (Primer + TC2, non-scribe); (b) $20 \mu \mathrm{m}$ TC3 topcoat (Primer + TC3, non-scribe); (c) $30 \mu \mathrm{m}$ TC4 topcoat (Primer + TC4, non-scribe)) after the accelerated exposure corrosion test of two-coat system without scribe. The values indicated below the images are the percentages of white rust area over the total area.

As summarized, the developed two-coat system with zinc rich primer and sol-gel topcoat performed well in both corrosion protection and color retaining aspects. The sacrificial corrosion protection was well retained with limited white rust observed after 84 days of exposure under accelerated conditions. Furthermore, the developed two-coat system had a significantly higher application productivity than the current multi-layer coating systems.

\subsection{Electrochemical Impedance Spectroscopy (EIS) Study on Ce-BTN/Mo-HT Incorporated Sol-Gel Coatings}

The Ce-BTN or Mo-HT were incorporated into the sol-gel coatings for further investigation on the influences of corrosion inhibitors on the corrosion protection performance. Different coatings were prepared, as described in Table 3. The performance of the coated samples was studied using EIS for an immersion up to $20 \mathrm{~h}$ in $0.1 \mathrm{wt} . \% \mathrm{NaCl}$ solution. Impedance data were recorded throughout the entire duration $(20 \mathrm{~h})$ with a $1 \mathrm{~h}$ interval, to gain an insight into the initial performance of the coated samples.

Table 3. Description of coatings for EIS study.

\begin{tabular}{cc}
\hline Sample ID & Coating Description (Directly on Carbon Steel) \\
\hline S1 & Original sol-gel coating \\
S2 & Sol-gel coating incorporated with $0.2 \mathrm{wt} \%$ Ce-BTN \\
S3 & Sol-gel coating incorporated with $0.2 \mathrm{wt.} \% \mathrm{Mo}-\mathrm{HT}$ \\
S4 & Sol-gel coating incorporated with $0.5 \mathrm{wt} . \%$ Ce-BTN \\
\hline
\end{tabular}

Figure 4a-c present the Bode plots of the S1, S2 and S3 after an immersion in $0.1 \mathrm{wt} . \%$ chloride solution for 1, 10 and $20 \mathrm{~h}$ respectively. Moutarlier et al. [40] and Yasakau et al. [41] suggested that the addition of certain types of inhibitors/additives to sol-gel coatings may disrupt the stability of the sol-gel matrix, which can lead to the weakening of its corrosion protection abilities. It was discussed that the reduced performance is related to the high solubility of ions and the precipitation of foreign particles $[40,41]$. However, from the results in Figure 4 , all the coating systems demonstrated generally high impedance values $\left(10^{7}\right)$, comparable with the reported data for sol-gel based coatings [24,27,42]. The relatively high impedance values of the coating systems demonstrated that the addition of a relatively low concentration of inhibitors did not degrade the initial protection properties of sol-gel coatings. 

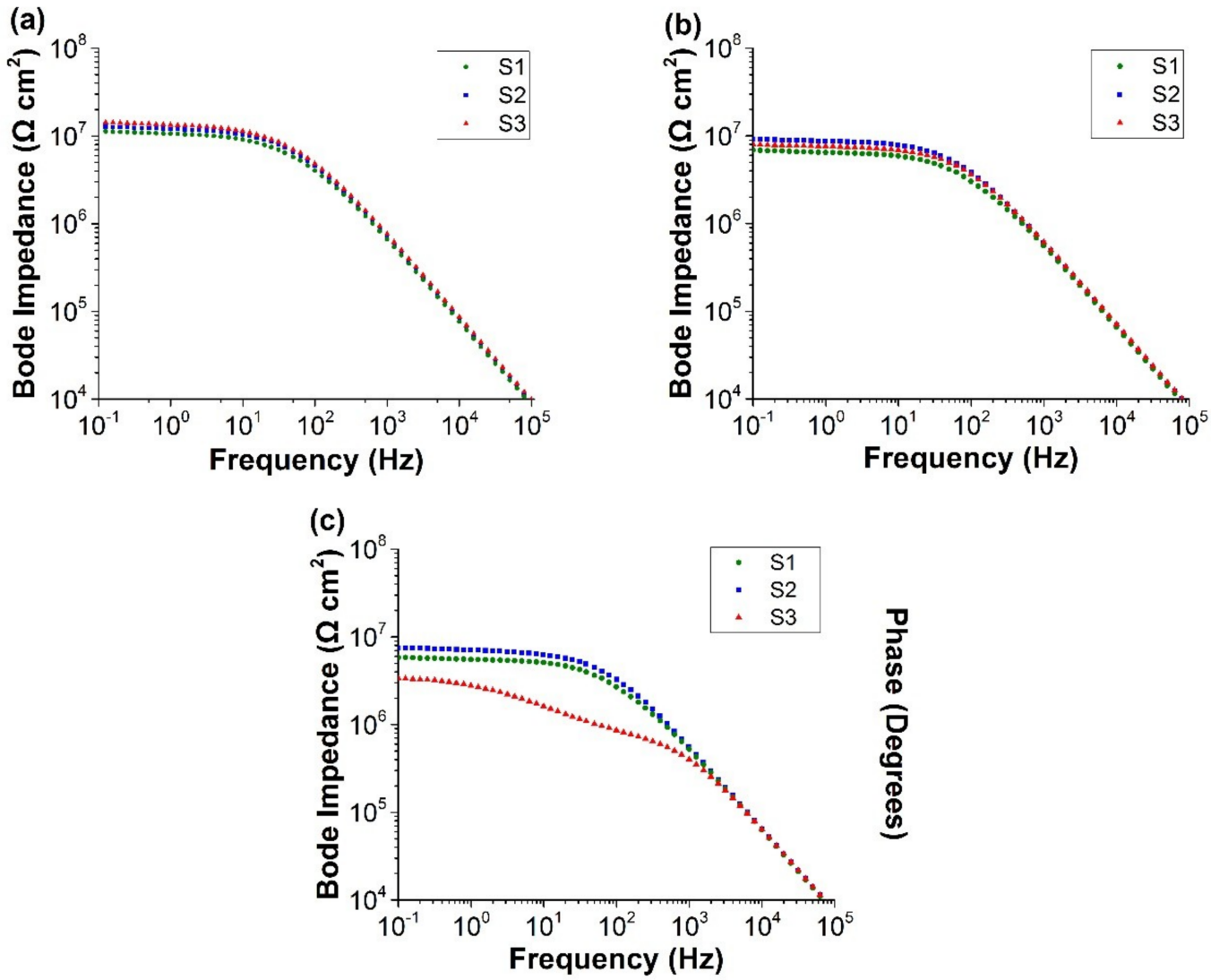

Figure 4. Bode plots of the three different coating systems after; (a) $1 \mathrm{~h}$ immersion, (b) $10 \mathrm{~h}$ immersion, and (c) $20 \mathrm{~h}$ immersion in $0.1 \mathrm{wt} . \% \mathrm{NaCl}$ solution.

Comparing the impedance values in Figure $4 \mathrm{a}$, we find that the corrosion resistance of S3 $\left(1.4 \times 10^{7} \Omega \cdot \mathrm{cm}^{2}\right)$ is slightly higher than that of S2 $\left(1.1 \times 10^{7} \Omega \cdot \mathrm{cm}^{2}\right)$ and S1 $\left(1.0 \times 10^{7} \Omega \cdot \mathrm{cm}^{2}\right)$ after $1 \mathrm{~h}$ immersion in chloride solution. Figure $4 \mathrm{~b}$ depicts the corrosion resistance of the coating systems after an immersion of $10 \mathrm{~h}$ in $0.1 \mathrm{wt} . \% \mathrm{NaCl}$ solution. Generally, it shows a decrease in the impedance magnitude of all the coated samples after $10 \mathrm{~h}$ immersion in the chloride solution, compared to the results obtained after $1 \mathrm{~h}$ immersion. However, there was a rearrangement in the corrosion performance ranking based on the impedance values with S2 $\left(9.7 \times 10^{6} \Omega \cdot \mathrm{cm}^{2}\right)$ exhibiting the highest corrosion resistance, followed by S3 $\left(8.5 \times 10^{6} \Omega \cdot \mathrm{cm}^{2}\right)$ and then S1 $\left(7.4 \times 10^{6} \Omega \cdot \mathrm{cm}^{2}\right)$. Lastly, Figure $4 \mathrm{c}$ illustrates all the coating resistance values after $20 \mathrm{~h}$ immersion and the ranking in terms of their impedance values as $\mathrm{S} 2>\mathrm{S} 1>\mathrm{S} 3$.

As observed in Figure 4a, the higher impedance magnitude $(|Z|)$ of S3 can be associated with the quick release of molybdate into the system, which may have helped to passivate and strengthen the interface between the coating and the carbon steel substrate. Furthermore, the addition of hydrotalcite, which was used as an inhibitor carrier, helps to adsorb chloride ions through an ions exchange, reducing the amount of chloride ions from reaching the substrate surface [43,44]. This could explain the higher initial impedance exhibited by S3. On the other hand, there was a significant decrease in impedance of S3 after $20 \mathrm{~h}$ immersion as seen in Figure 4c. The majority of the loaded molybdate ions having already exchanged with $\mathrm{Cl}^{-}$could be the main reason for this observation.

The higher resistance observed in S2 compared to S3 after $20 \mathrm{~h}$ immersion can be attributed to the controlled release of cerium ions from the sol-gel coating. It is widely discussed and known that the addition of cerium ions results in the precipitation of cerium oxides on cathodic sites, preventing oxygen reduction $[1,24,45-48]$. This could result in the higher impedance values recorded by $\mathrm{S} 2$ after $20 \mathrm{~h}$ immersion in $0.1 \mathrm{wt} . \% \mathrm{NaCl}$. To further investigate on the electrochemical impedance behavior of the coating systems, an equivalent circuit is deployed, as shown in Figure 5. 


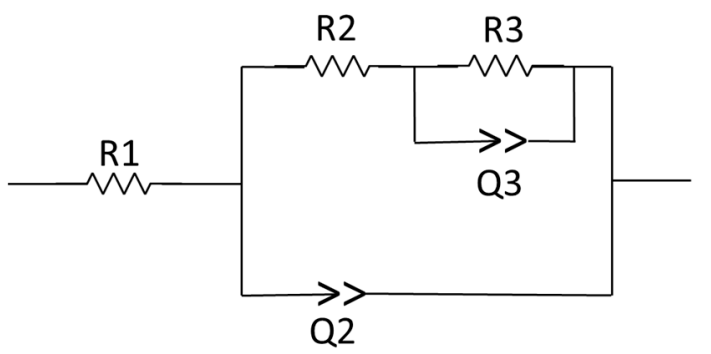

Figure 5. Equivalent circuit used for fitting of EIS data.

The equivalent circuits used for studies in inhibitors incorporated sol-gel coatings have been extensively described by Ferreira et al. [1,49], Trabelsi et al. [24] and Wang et al. [42]. It is reported that the second time constant may represent charge transfer regions, an oxide layer, or an intermediate layer [42]. A two-time constant model is proposed in this study with the second time constant is assigned to represent an intermediate layer. A similar approach was been made by Wang et al. [42], associating the second time constant as an intermediate layer. Pure capacitance elements are replaced by constant phase elements in the equivalent circuit. Figure 5 shows the circuit elements used in the equivalent circuit; (i) $R_{1}=$ electrolyte resistance, (ii) $R_{2}=$ coating resistance, pore structure of coating is accounted in this element, (iii) $Q_{2}=$ constant phase element related to coating, (iv) $R_{3}=$ resistance of intermediate that forms between coating and metallic substrate, $(\mathrm{v}) Q_{3}=$ constant phase element related to intermediate layer. Consequently, the experimental results were simulated based on this circuit to obtain the values of each element. The proposed equivalent circuit simulates and fits well with the Nyquist plot, as observed in Figure 6.

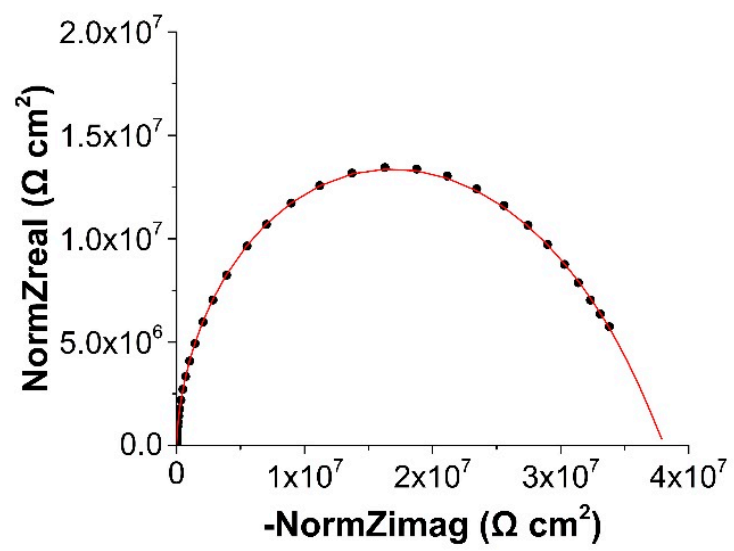

Figure 6. Nyquist plot of S4 fitted using the equivalent circuit (Figure 2) after immersing for $1 \mathrm{~h}$ in 0.1 wt. $\% \mathrm{NaCl}$.

For further investigation of the behavior of the coating, the change of $R_{2}$ and $R_{3}$ values along the exposure time are plotted along the exposure time in Figure 7. The coating with $0.2 \mathrm{wt} . \%$ Mo-HT (S3) shows the highest resistance with the highest $R_{3}$ values up to the first five hours of immersion, as seen in Figure $7 \mathrm{~b}$. However, after $20 \mathrm{~h}$ immersion in chloride solution, both $R_{2}$ and $R_{3}$ values for $\mathrm{S} 3$ declined significantly. Notably, the $R_{2}$ and $R_{3}$ values of Mo-HT loaded coating (S3) was even lower than the coating without any inhibitor added (S1). This suggests that the addition of molybdate may have an adverse effect on the corrosion protective properties of sol-gel coating. Nevertheless, the coating with $0.2 \mathrm{wt} . \%$ Ce-BTN (S2) shows comparatively less reduction in $R_{2}$ values and at the same time, achieved the highest resistance values after $20 \mathrm{~h}$ immersion. The values of $R_{2}$ of S2 were relatively stable, indicating a very stable intermediate layer. 

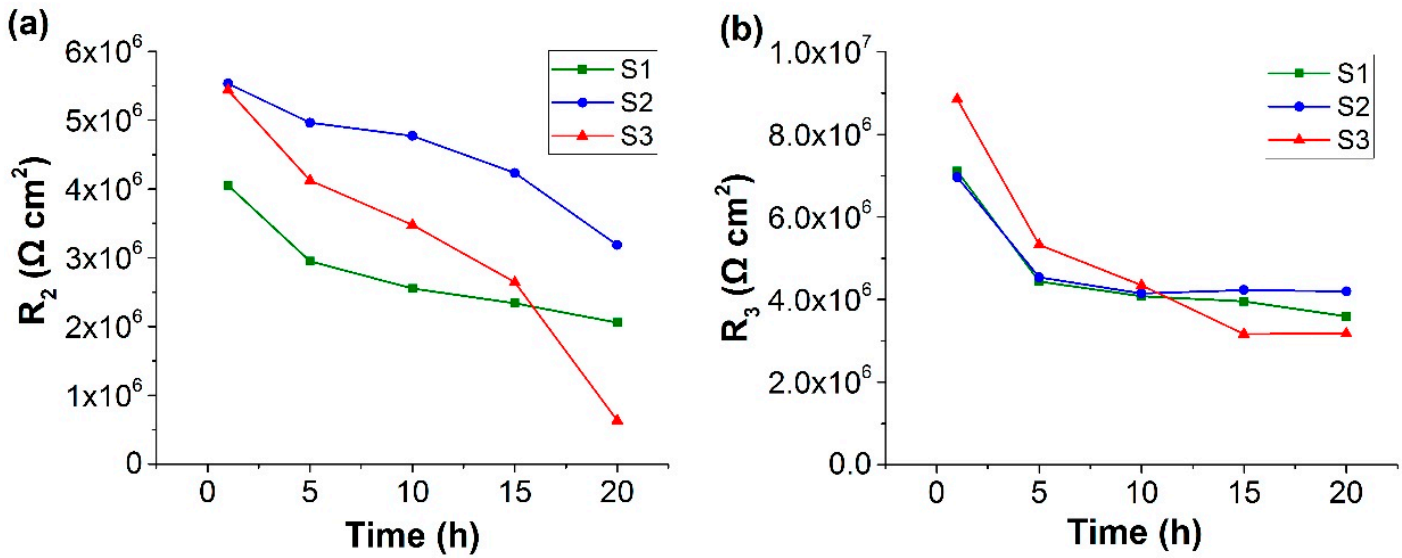

Figure 7. Evolution of fitting parameters for S1, S2 \& S3 using the equivalent circuits in Figure 5 following $20 \mathrm{~h}$ immersion in $0.1 \mathrm{wt} . \% \mathrm{NaCl}$ Solutions. (a) Coating resistance $R_{2}$ and (b) intermediate layer resistance $R_{3}$.

The effects of cerium salts as a corrosion inhibitor on various metal alloys have been heavily studied by researchers. The mechanism of its inhibition was reported by Hinton [50] and Montemor et al. $[1,24,45]$. Montemor suggested that the main form of protection arises from the precipitation of cerium oxide/hydroxide on cathodic sites which minimizes oxygen reduction from occurring. As cerium nitrate readily dissolves in an aqueous solution, it leads to the release of $\mathrm{Ce}^{3+}$ into the system. $\mathrm{Ce}^{3+}$ preferentially forms $\mathrm{Ce}(\mathrm{OH})_{3}$ in the presence of hydroxide ions $\left(\mathrm{OH}^{-}\right)$. As $\mathrm{Ce}(\mathrm{OH})_{3}$ is readily available, it may react with hydroxide ions to precipitate cerium oxide $\left(\mathrm{CeO}_{2}\right)$, covering the cathodic regions and also hindering its counter anodic reactions (oxidation of $\mathrm{Fe}^{\mathrm{to}} \mathrm{Fe}^{2+}$ ) to prevent further corrosion from occurring. Furthermore, as reported by Barranco et al. [20], the formation of the $\mathrm{CeO}_{2}$ precipitates may help to block the pores of the bottom most layer in the porous sol-gel coating, which helps to slow down the corrosion process. The EIS results depicted in Figure 7 support the work by Montemor and Barranco, with the highest $R_{2} \& R_{3}$ values of S2 compared to that of S1 and S3 along prolong exposure in $0.1 \mathrm{wt} . \%$ chloride solution.

Environmental friendly corrosion inhibitors, such as molybdate, have been successfully incorporated into various protection systems [51,52]. $\mathrm{MoO}_{4}{ }^{2-}$ is a non-oxidizing (anodic) inhibitor that requires the presence of oxygen or an oxidizing agent for passivation to occur on metal surfaces. It is reported that its inhibition effect is due to the adsorption of $\mathrm{MoO}_{4}{ }^{2-}$ ions onto the steel surfaces that was followed by the reduction of $\mathrm{MoO}_{4}{ }^{2-}$ to $\mathrm{MoO}_{2}$. The reduction reaction also helps to reduce the localized aggressive environment through the reduction in $\mathrm{H}^{+}$ions [53-56]. It was also suggested that the precipitation of $\mathrm{FeMoO}_{4}$ helps to re-passivate active sites, forming a thin film that inhibits corrosion [57]. The addition of sodium molybdate into the coating (S3) is evident in Figure 7 as higher impedance readings were observed compared to S1. As discussed earlier, the higher $R_{3}$ values of S3 may be due to the fast release of the molybdate ions from S3, which resulted in the strengthening of the intermediate layer between the coating and substrate. However, when most of molybdate within the effective area was consumed and not replenished after prolonged exposure, the intermediate layer may have weakened and lost its resistance, which is evident as both $R_{2}$ and $R_{3}$ values of S3 decreased significantly after $20 \mathrm{~h}$ immersion. These results coincide well with the work reported by Moutarlier and Voevodin $[40,58]$. It was suggested that the presence of molybdate inhibitors leads to the disruption of sol-gel coating, affecting its corrosion protection properties.

After confirming the better effect in terms of potential long term corrosion protection of Ce-BTN than Mo-HT based on EIS results, further studies were designed to investigate the effect of the concentration of Ce-BTN in sol-gel coatings. The concentration of Ce-BTN was increased from 0.2 to $0.5 \mathrm{wt} . \%$ while keeping the same coating thickness. Figure 8 shows the Bode plot of two concentrations of Ce-BTN (0.2 \& $0.5 \mathrm{wt} . \%)$ after $2 \mathrm{~h}$ immersion in $0.1 \mathrm{wt} . \%$ chloride solution. The coating with $0.5 \mathrm{wt} . \%$ 
cerium concentration (S4) shows higher total impedance, implying that the increase in cerium content may help to enhance the corrosion protection properties of sol-gel coatings. The total impedance of S4 is around $3.9 \times 10^{7} \Omega \cdot \mathrm{cm}^{2}$ which was one order of magnitude higher than that of S2 which is around $7.2 \times 10^{6} \Omega \cdot \mathrm{cm}^{2}$ as depicted in Figure 8 .

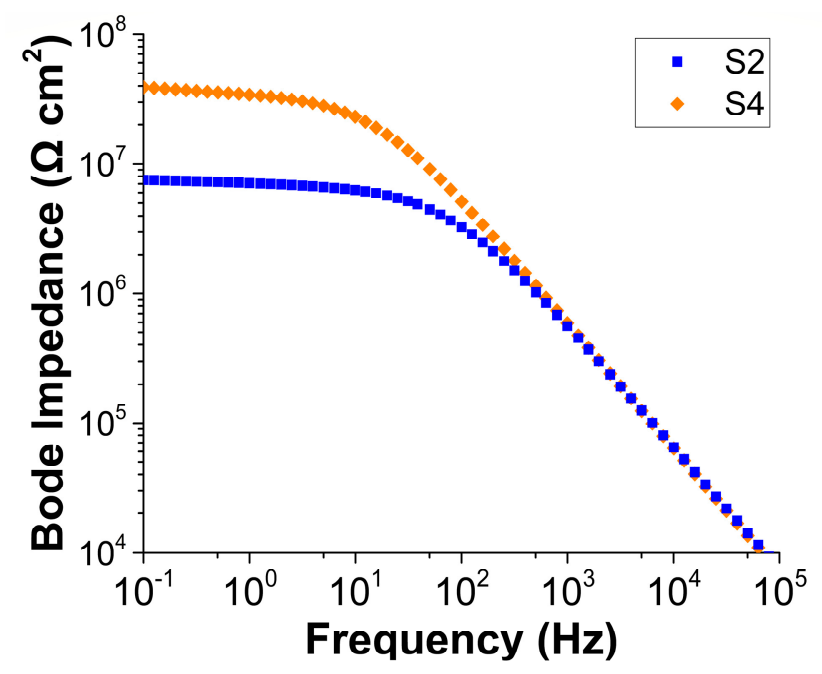

Figure 8. Bode plots of S2 \& S4 after $20 \mathrm{~h}$ immersion in $0.1 \mathrm{wt} . \% \mathrm{NaCl}$.

To analyze the behavior of the effects of Ce-BTN concentration on the coating performance along with exposure time, changes in $R_{2}$ and $R_{3}$ values obtained through numerical fitting of the Bode plots using the equivalent circuit are presented in Figure 9. The difference in the $R_{2}$ and $R_{3}$ readings of $\mathrm{S} 2$ \& S4 were compelling, with the later showing greater superiority in its ability to resist corrosion. In addition, the $R_{2}$ values of $S 4$ increased along the immersion period (up to the first $10 \mathrm{~h}$ ). With the release of a higher amount of $\mathrm{Ce}^{3+}$, it leads to increase in formation of hydroxides/oxides. This helps to block the bottom of the linked pores in the sol-gel coating which could be the reason for the increase in corrosion resistance. These results are in good agreement with the work covered by Trabelsi et al. [24] and Barranco et al. [20]. Furthermore, higher numbers of inhibitors may also provide a better coverage of the effective area with the same number of pores. As evidenced in this study, the incorporation of Ce-BTN helped to improve the corrosion protection properties of sol-gel coatings.
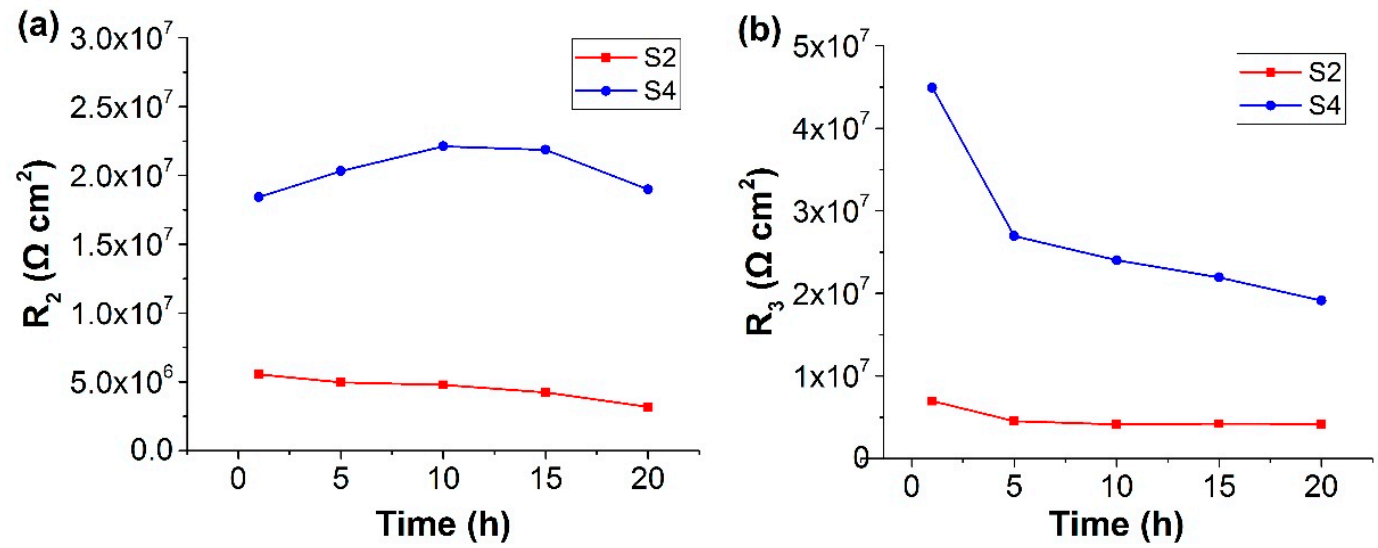

Figure 9. Change of fitting parameters: (a) coating resistance $R_{2}$ and (b) intermediate layer resistance $R_{3}$ of $\mathrm{S} 2$ and $\mathrm{S} 4$ along the exposure time (up to $20 \mathrm{~h}$ of immersion) in $0.1 \mathrm{wt} . \% \mathrm{NaCl}$ solutions. 


\section{Conclusions}

In this work, the development of a two-coat corrosion protective system with a sol-gel topcoat on zinc rich primer is investigated. The developed sol-gel topcoat provides an aesthetic presence to the coating system without an adverse effect on the corrosion protection performance, especially on the sacrificial corrosion protection capability of the zinc rich primer. Coating systems were assessed by accelerated corrosion exposure and subsequent coating performance evaluation. The investigation of the parameters of sol-gel coating application suggested that a higher curing temperature of the sol-gel significantly reduced the white rust formation due to the underlying zinc primer, whilst longer curing duration also can be an alternative solution.

As another step forward, corrosion inhibitors were incorporated into the sol-gel coating, aiming to provide additional inhibitive corrosion protection. In order to reduce the negative effect on the stability of the sol-gel coating, inhibitors were loaded onto suitable inorganic oxide carriers before being incorporated into the sol-gel coating. The total impedance of the coating with Ce-BTN $\left(7.2 \times 10^{6} \Omega \cdot \mathrm{cm}^{2}\right)$ was superior to the coatings with Mo-HT $\left(3.3 \times 10^{6} \Omega \cdot \mathrm{cm}^{2}\right)$ and without inhibitors $\left(5.7 \times 10^{6} \Omega \cdot \mathrm{cm}^{2}\right)$ after $20 \mathrm{~h}$ immersion in $0.1 \mathrm{wt} . \%$ chloride solution. Moreover, the concentration of $\mathrm{Ce}^{3+}$ was investigated and found that the coating with $0.5 \mathrm{wt} . \%$ cerium concentration was one order of magnitude higher than that of $0.2 \mathrm{wt} . \%$ cerium concentration after $20 \mathrm{~h}$ immersion. Electrochemical impedance spectroscopy (EIS) results clearly demonstrated the improvement of corrosion protection due to the incorporation of inhibitor loaded materials.

Further investigations and developments are in progress to achieve the best overall performance of the coating systems by optimizing the concentrations of inhibitors in each case without compromising other physical and mechanical properties of the coating system. The investigation on the two-coat system of the inhibitor loaded colored sol-gel on the zinc primer will be carried on. The corrosion mechanism and incorporation of two layers will be studied.

Author Contributions: Conceptualization, S.L.W. and L.Y.W.; Methodology, W.Y. and W.K.O.; Validation, W.Y. and W.K.O.; Formal Analysis, W.Y. and W.K.O.; Investigation, W.Y. and W.K.O.; Writing-Original Draft Preparation W.Y. and W.K.O.; Writing-Review \& Editing, S.L.W. and L.Y.W.; Funding Acquisition, S.L.W. and L.Y.W.

Funding: This research was funded by the Building and Construction Authority of Singapore for the support of this project under a research fund by the Ministry of National Development, Singapore.

Acknowledgments: We appreciate the great support from our industrial collaborators: ZINGAMETALL (Singapore) Pte Ltd. and FRP Products Co Pte Ltd.

Conflicts of Interest: The authors declare no conflict of interest. The founding sponsors had no role in the design of the study; in the collection, analyses, or interpretation of data; in the writing of the manuscript, and in the decision to publish the results.

\section{References}

1. Zheludkevich, M.L.; Serra, R.; Montemor, M.F.; Yasakau, K.A.; Salvado, I.M.M.; Ferreira, M.G.S. Nanostructured sol-gel coatings doped with cerium nitrate as pre-treatments for AA2024-T3: Corrosion protection performance. Electrochim. Acta 2005, 51, 208-217. [CrossRef]

2. Joshua Du, Y.; Damron, M.; Tang, G.; Zheng, H.; Chu, C.-J.; Osborne, J.H. Inorganic/organic hybrid coatings for aircraft aluminum alloy substrates. Prog. Org. Coat. 2001, 41, 226-232. [CrossRef]

3. Hofacker, S.; Mechtel, M.; Mager, M.; Kraus, H. Sol-gel: A new tool for coatings chemistry. Prog. Org. Coat. 2002, 45, 159-164. [CrossRef]

4. Wang, H.; Akid, R.; Gobara, M. Scratch-resistant anticorrosion sol-gel coating for the protection of AZ31 magnesium alloy via a low temperature sol-gel route. Corros. Sci. 2010, 52, 2565-2570. [CrossRef]

5. Prado, R.; Beobide, G.; Marcaide, A.; Goikoetxea, J.; Aranzabe, A. Development of multifunctional sol-gel coatings: Anti-reflection coatings with enhanced self-cleaning capacity. Sol. Energy Mater. Sol. Cells 2010, 94, 1081-1088. [CrossRef]

6. Wang, D.; Bierwagen, G.P. Sol-gel coatings on metals for corrosion protection. Prog. Org. Coat. 2009, 64, 327-338. [CrossRef] 
7. Guglielmi, M. Sol-gel coatings on metals. J. Sol-Gel Sci. Technol. 1997, 8, 443-449. [CrossRef]

8. Rao, A.V.; Latthe, S.S.; Mahadik, S.A.; Kappenstein, C. Mechanically stable and corrosion resistant superhydrophobic sol-gel coatings on copper substrate. Appl. Surf. Sci. 2011, 257, 5772-5776. [CrossRef]

9. Zheludkevich, M.L.; Shchukin, D.G.; Yasakau, K.A.; Möhwald, H.; Ferreira, M.G.S. Anticorrosion coatings with self-healing effect based on nanocontainers impregnated with corrosion inhibitor. Chem. Mater. 2007, 19, 402-411. [CrossRef]

10. Alibakhshi, E.; Akbarian, M.; Ramezanzadeh, M.; Ramezanzadeh, B.; Mahdavian, M. Evaluation of the corrosion protection performance of mild steel coated with hybrid sol-gel silane coating in $3.5 \mathrm{wt} . \% \mathrm{NaCl}$ solution. Prog. Org. Coat. 2018, 123, 190-200. [CrossRef]

11. Tan, A.L.K.; Soutar, A.M.; Annergren, I.F.; Liu, Y.N. Multilayer sol-gel coatings for corrosion protection of magnesium. Surf. Coat. Technol. 2005, 198, 478-482. [CrossRef]

12. Shen, G.X.; Chen, Y.C.; Lin, C.J. Corrosion protection of $316 \mathrm{~L}$ stainless steel by a $\mathrm{TiO}_{2}$ nanoparticle coating prepared by sol-gel method. Thin Solid Films 2005, 489, 130-136. [CrossRef]

13. Vijayalakshmi, U.; Rajeswari, S. Synthesis and characterization of sol-gel derived glass-ceramic and its corrosion protection on 316L SS. J. Sol-Gel Sci. Technol. 2007, 43, 251-258. [CrossRef]

14. Jianguo, L.; Gaoping, G.; Chuanwei, Y. Enhancement of the erosion-corrosion resistance of Dacromet with hybrid $\mathrm{SiO}_{2}$ sol-gel. Surf. Coat. Technol. 2006, 200, 4967-4975. [CrossRef]

15. Fedel, M.; Poelman, M.; Zago, M.; Vandermiers, C.; Cossement, D.; Olivier, M.-G.; Deflorian, F. Influence of formulation and application parameters on the performances of a sol-gel/clay nanocomposite on the corrosion resistance of hot-dip galvanized steel. Part II. Effect of curing temperature and time. Surf. Coat. Technol. 2015, 274, 9-17. [CrossRef]

16. Mrad, M.; Dhouibi, L.; Montemor, M.F. Elaboration of $\gamma$-glycidoxypropyltrimethoxysilane coating on AA2024-T3 aluminum alloy: Influence of synthesis route on physicochemical and anticorrosion properties. Prog. Org. Coat. 2018, 121, 1-12. [CrossRef]

17. Mrad, M.; Ben Amor, Y.; Dhouibi, L.; Montemor, M.F. Effect of AA2024-T3 surface pretreatment on the physicochemical properties and the anticorrosion performance of poly $(\gamma$-glycidoxypropyltrimethoxysilane) sol-gel coating. Surf. Interface Anal. 2017, 50, 335-345. [CrossRef]

18. Zhao, H.; Yu, M.; Liu, J.; Li, S.; Xue, B.; Liang, M. Effect of surface roughness on corrosion resistance of sol-gel coatings on AA2024-T3 alloy. J. Electrochem. Soc. 2015, 162, C718-C724. [CrossRef]

19. Yasakau, K.A.; Carneiro, J.; Zheludkevich, M.L.; Ferreira, M.G.S. Influence of sol-gel process parameters on the protection properties of sol-gel coatings applied on AA2024. Surf. Coat. Technol. 2014, 246, 6-16. [CrossRef]

20. Barranco, V.; Feliu, S., Jr.; Galvan, J.C.; Carmona, N.; Sanchez-Majado, S.; Jimenez-Morales, A. Cerium doped hybrid silica sol-gel coatings with selfhealing properties for corrosion protection of mild steel. In Proceedings of the 17th International Corrosion Congress 2008: Corrosion Control in the Service of Society, Las Vegas, NV, USA, 6-10 October 2008; Volume 5, pp. 3197-3229.

21. Baldin, E.K.K.; Kunst, S.R.; Beltrami, L.V.R.; Lemos, T.M.; Quevedo, M.C.; Bastos, A.C.; Ferreira, M.G.S.; Santos, P.R.R.; Sarmento, V.H.V.; Malfatti, C.D.F. Ammonium molybdate added in hybrid films applied on tinplate: Effect of the concentration in the corrosion inhibition action. Thin Solid Films 2016, 600, 146-156. [CrossRef]

22. Maia, F.; Yasakau, K.A.; Carneiro, J.; Kallip, S.; Tedim, J.; Henriques, T.; Cabral, A.; Venâncio, J.; Zheludkevich, M.L.; Ferreira, M.G.S. Corrosion protection of AA2024 by sol-gel coatings modified with MBT-loaded polyurea microcapsules. Chem. Eng. J. 2016, 283, 1108-1117. [CrossRef]

23. Dias, S.A.S.; Lamaka, S.V.; Diamantino, T.C.; Ferreira, M.G.S. Synergistic protection against corrosion of aa2024-t3 by sol-gel coating modified with La and Mo-enriched zeolites. J. Electrochem. Soc. 2014, 161, C215-C222. [CrossRef]

24. Trabelsi, W.; Cecilio, P.; Ferreira, M.G.S.; Montemor, M.F. Electrochemical assessment of the self-healing properties of Ce-doped silane solutions for the pre-treatment of galvanised steel substrates. Prog. Org. Coat. 2005, 54, 276-284. [CrossRef]

25. Snihirova, D.; Lamaka, S.V.; Montemor, M.F. "SMART" protective ability of water based epoxy coatings loaded with $\mathrm{CaCO}_{3}$ microbeads impregnated with corrosion inhibitors applied on AA2024 substrates. Electrochim. Acta 2012, 83, 439-447. [CrossRef] 
26. Montemor, M.F.; Snihirova, D.V.; Taryba, M.G.; Lamaka, S.V.; Kartsonakis, I.A.; Balaskas, A.C.; Kordas, G.C.; Tedim, J.; Kuznetsova, A.; Zheludkevich, M.L.; et al. Evaluation of self-healing ability in protective coatings modified with combinations of layered double hydroxides and cerium molibdate nanocontainers filled with corrosion inhibitors. Electrochim. Acta 2012, 60, 31-40. [CrossRef]

27. Zheludkevich, M.L.; Tedim, J.; Ferreira, M.G.S. "Smart" coatings for active corrosion protection based on multi-functional micro and nanocontainers. Electrochim. Acta 2012, 82, 314-323. [CrossRef]

28. Carneiro, J.; Caetano, A.F.; Kuznetsova, A.; Maia, F.; Salak, A.N.; Tedim, J.; Scharnagl, N.; Zheludkevich, M.L.; Ferreira, M.G.S. Polyelectrolyte-modified layered double hydroxide nanocontainers as vehicles for combined inhibitors. RSC Adv. 2015, 5, 39916-39929. [CrossRef]

29. Snihirova, D.; Lamaka, S.V.; Taryba, M.; Salak, A.N.; Kallip, S.; Zheludkevich, M.L.; Ferreira, M.G.S.; Montemor, M.F. Hydroxyapatite microparticles as feedback-active reservoirs of corrosion inhibitors. ACS Appl. Mater. Interfaces 2010, 2, 3011-3022. [CrossRef]

30. Rosero-Navarro, N.C.; Figiel, P.; Jedrzejewski, R.; Biedunkiewicz, A.; Castro, Y.; Aparicio, M.; Pellice, S.A.; Durán, A. Influence of cerium concentration on the structure and properties of silica-methacrylate sol-gel coatings. J. Sol-Gel Sci. Technol. 2010, 54, 301-311. [CrossRef]

31. Trenado, C.; Wittmar, M.; Veith, M.; Rosero-Navarro, N.C.; Aparicio, M.; Durán, A.; Castro, Y.; Strauss, D.J. Multiscale numerical modeling of $\mathrm{Ce}^{3+}$-inhibitor release from novel corrosion protection coatings. Model. Simul. Mater. Sci. Eng. 2011, 19, 25009. [CrossRef]

32. Rosero-Navarro, N.C.; Pellice, S.A.; Durán, A.; Aparicio, M. Effects of Ce-containing sol-gel coatings reinforced with $\mathrm{SiO} 2$ nanoparticles on the protection of AA2024. Corros. Sci. 2008, 50, 1283-1291. [CrossRef]

33. Rosero-Navarro, N.C.; Pellice, S.A.; Durán, A.; Ceré, S.; Aparicio, M. Corrosion protection of aluminium alloy AA2024 with cerium doped methacrylate-silica coatings. J. Sol-Gel Sci. Technol. 2009, 52, 31-40. [CrossRef]

34. Bohm, S.; McMurray, H.N.; Worsley, D.A.; Powell, S.M. Novel environment friendly corrosion inhibitor pigments based on naturally occurring clay minerals. Mater. Corros. 2001, 52, 896-903. [CrossRef]

35. ISO 8501-1:2007 Preparation of Steel Substrates before Application of Paints and Related Products_Visual Assessment of Surface Cleanliness-Part 1: Rust Grades and Preparation Grades of Uncoated Steel Substrates and of Steel Substrates after Overall Removal of Previous Coatings; ISO: Geneva, Switzerland, 2007. Available online: https:/ / www.iso.org/obp/ui/\#iso:std:iso:8501:-1:ed-2:v1:en (accessed on 30 November 2018).

36. Wu, L.Y.L.; Chwa, E.; Chen, Z.; Zeng, X.T. A study towards improving mechanical properties of sol-gel coatings for polycarbonate. Thin Solid Films 2008, 516, 1056-1062. [CrossRef]

37. ASTM D3363 - 05(2011)e2 Standard Test Method for Film Hardness by Pencil Test; ASTM International: West Conshohocken, PA, USA, 2011. Available online: https:/ / www.astm.org/Standards/D3363.htm (accessed on 30 November 2018).

38. ASTM D3359-17 Standard Test Methods for Rating Adhesion by Tape Test; ASTM International: West Conshohocken, PA, USA, 2017. Available online: https://www.astm.org/Standards/D3359.htm (accessed on 30 November 2018).

39. Mackenzie, J.D.; Bescher, E.P. Physical properties of sol-gel coatings. J. Sol-Gel Sci. Technol. 2000, 19, 23-29. [CrossRef]

40. Moutarlier, V.; Neveu, B.; Gigandet, M.P. Evolution of corrosion protection for sol-gel coatings doped with inorganic inhibitors. Surf. Coat. Technol. 2008, 202, 2052-2058. [CrossRef]

41. Yasakau, K.A.; Zheludkevich, M.L.; Karavai, O.V.; Ferreira, M.G.S. Influence of inhibitor addition on the corrosion protection performance of sol-gel coatings on AA2024. Prog. Org. Coat. 2008, 63, 352-361. [CrossRef]

42. Wang, H.; Akid, R. Encapsulated cerium nitrate inhibitors to provide high-performance anti-corrosion sol-gel coatings on mild steel. Corros. Sci. 2008, 50, 1142-1148. [CrossRef]

43. Xu, J.; Song, Y.; Tan, Q.; Jiang, L. Chloride absorption by nitrate, nitrite and aminobenzoate intercalated layered double hydroxides. J. Mater. Sci. 2017, 52, 5908-5916. [CrossRef]

44. Mahajanam, S.P.V. Application of Hydrotalcites as Corrosion-Inhibiting Pigments in Organic Coatings. Ph.D. Thesis, The Ohio State University, Columbus, OH, USA, 2005.

45. Garcia-Heras, M.; Jimenez-Morales, A.; Casal, B.; Galvan, J.C.; Radzki, S.; Villegas, M.A. Preparation and electrochemical study of cerium-silica sol-gel thin films. J. Alloys Compd. 2004, 380, 219-224. [CrossRef]

46. Arenas, M.A.; de Damborenea, J.J. Growth mechanisms of cerium layers on galvanised steel. Electrochim. Acta 2003, 48, 3693-3698. [CrossRef] 
47. Fedel, M.; Callone, E.; Fabbian, M.; Deflorian, F.; Dirè, S. Influence of $\mathrm{Ce}^{3+}$ doping on molecular organization of Si-based organic/inorganic sol-gel layers for corrosion protection. Appl. Surf. Sci. 2017, 414, 82-91. [CrossRef]

48. Santana, I.; Pepe, A.; Jimenez-Pique, E.; Pellice, S.; Milošev, I.; Ceré, S. Corrosion protection of carbon steel by silica-based hybrid coatings containing cerium salts: Effect of silica nanoparticle content. Surf. Coat. Technol. 2015, 265, 106-116. [CrossRef]

49. Wang, J.-X.; Wang, Z.-H.; Chen, J.-F.; Yun, J. Direct encapsulation of water-soluble drug into silica microcapsules for sustained release applications. Mater. Res. Bull. 2008, 43, 3374-3381. [CrossRef]

50. Hinton, B.R.W. Corrosion inhibition with rare earth metal salts. J. Alloys Compd. 1992, 180, 15-25. [CrossRef]

51. Kakaroglou, A.; Domini, M.; De Graeve, I. Encapsulation and incorporation of sodium molybdate in polyurethane coatings and study of its corrosion inhibition on mild steel. Surf. Coat. Technol. 2016, 303, 330-341. [CrossRef]

52. Mekeridis, E.D.; Kartsonakis, I.A.; Kordas, G.C. Multilayer organic-inorganic coating incorporating TiO2 nanocontainers loaded with inhibitors for corrosion protection of AA2024-T3. Prog. Org. Coat. 2012, 73, 142-148. [CrossRef]

53. Vukasovich, M.S.; Farr, J.P.G. Molybdate in corrosion inhibition-A review. Polyhedron 1986, 5, 551-559. [CrossRef]

54. Ilevbare, G.O.; Burstein, G.T. The inhibition of pitting corrosion of stainless steels by chromate and molybdate ions. Corros. Sci. 2003, 45, 1545-1569. [CrossRef]

55. Shams El Din, A.M.; Wang, L. Mechanism of corrosion inhibition by sodium molybdate. Desalination 1996, 107, 29-43. [CrossRef]

56. Tan, Y.T.; Wijesinghe, S.L.; Blackwood, D.J. Effect of Molybdate on the Passivation of Carbon Steel in Alkaline Solutions under Open-Circuit Conditions. J. Electrochem. Soc. 2016, 163, C649-C658. [CrossRef]

57. Virtanen, S.; Surber, B.; Nylund, P. Influence of $\mathrm{MoO}_{4}{ }^{2-}$ anion in the electrolyte on passivity breakdown of iron. Corros. Sci. 2001, 43, 1165-1177. [CrossRef]

58. Voevodin, N.N.; Grebasch, N.T.; Soto, W.S.; Arnold, F.E.; Donley, M.S. Potentiodynamic evaluation of sol-gel coatings with inorganic inhibitors. Surf. Coat. Technol. 2001, 140, 24-28. [CrossRef]

(C) 2019 by the authors. Licensee MDPI, Basel, Switzerland. This article is an open access article distributed under the terms and conditions of the Creative Commons Attribution (CC BY) license (http://creativecommons.org/licenses/by/4.0/). 